ARTICLE

DOI: $10.1038 / s 41467-018-03596-z$

\title{
Fluorescent label-free quantitative detection of nano-sized bioparticles using a pillar array
}

Kerwin Kwek Zeming ${ }^{1}$, Thoriq Salafi ${ }^{1,2}$, Swati Shikha ${ }^{1}$ \& Yong Zhang (1) 1,2

Disease diagnostics requires detection and quantification of nano-sized bioparticles including DNA, proteins, viruses, and exosomes. Here, a fluorescent label-free method for sensitive detection of bioparticles is explored using a pillar array with micrometer-sized features in a deterministic lateral displacement (DLD) device. The method relies on measuring changes in size and/or electrostatic charges of $1 \mu \mathrm{m}$ polymer beads due to the capture of target bioparticles on the surface. These changes can be sensitively detected through the lateral displacement of the beads in the DLD array, wherein the lateral shifts in the output translates to a quantitative measurement of bioparticles bound to the bead. The detection of albumin protein and nano-sized polymer vesicles with a concentration as low as $10 \mathrm{ng} \mathrm{mL}^{-1}(150 \mathrm{pM})$ and $3.75 \mu \mathrm{g} \mathrm{mL}^{-1}$, respectively, is demonstrated. This label-free method holds potential for point-of-care diagnostics, as it is low-cost, fast, sensitive, and only requires a standard laboratory microscope for detection.

\footnotetext{
${ }^{1}$ Department of Biomedical Engineering, Faculty of Engineering, National University of Singapore, Singapore 117583, Singapore. ${ }^{2}$ NUS Graduate School for Integrative Sciences and Engineering, National University of Singapore, Singapore 117456, Singapore. Correspondence and requests for materials should be addressed to Y.Z. (email: biezy@nus.edu.sg)
} 
D isease diagnosis requires identification and quantification of various bioparticles such as DNA, RNA, proteins, virus, exosomes, and bacteria. Current clinical laboratories use well-established sandwich assay, PCR, gel electrophoresis, and flow-cytometry methods for detection of these bioparticles ${ }^{1,2}$. However, these methods use fluorescent labels that increase detection cost and complexity by reliance on expensive optical systems and involvement of multiple sample processing steps requiring minimum sample volumes. Thus, fluorescent label-free bioparticle detection gains traction as an alternative means in disease diagnosis.

Technological advancement in label-free methods using microcantilever ${ }^{3}$, surface-enhanced Raman scattering (SERS) ${ }^{4}$, surface plasmon resonance $(\mathrm{SPR})^{5-7}$, magnetic beads ${ }^{8}$, electrochemical detection ${ }^{9}$, and quartz crystal microbalance ${ }^{10}$ provide real-time information on bioparticle interactions, resulting in greater understanding of biochemical functions, drug interactions, and sensitive quantification of these bioparticles. The biosensor tracks changes in biophysical interactions of binding events, mass changes, refractive index or chemical reactions, and transduces the information as mechanical, electrical, or optical signals, and have shown detection of proteins down to femtomolar levels. However, these techniques often require precision engineering of nano-features, complex optical setups, secondary antibodies in sandwich assays, novel nanoprobes (e.g., graphene oxide, carbon nanotubes, and gold nanorods) or additional amplification step such as aggregation of nanoparticles to reduce the limit of detection (LOD) ${ }^{11}$.

Deterministic lateral displacement (DLD) pillar array platforms have been used for size-sensitive separation of circulating tumour cells to bioparticles such as DNA and exosomes ${ }^{12-15}$. For a fixed critical DLD cut-off size $\left(D_{c}\right)$, larger particles get displaced laterally relative to particles smaller than the $D_{c}{ }^{16,17}$. To separate nano-sized particles, it is challenging and costly to operate due to nanofabrication, precision injection of sample, and low throughput due to the small gap size ${ }^{18}$. So far, DLD research has mainly been focused on bioparticle separation and potential use of this technique for detection has not been extensively explored $^{19,20}$.

Here, a fluorescent label-free method for sensitive detection of nano-sized proteins and polymer vesicles using a DLD pillar array with micrometer-sized features is demonstrated. Bioparticles of interest are captured or adsorbed onto polymer microbeads with specific ligands and detected quantitatively based on lateral displacement of the microbeads in the pillar array. Two domains exist for this bioparticle detection phenomenon: for small bioparticles, electrostatic interactions dominate, and for large bioparticles, physical particle size increase has a dominant role. The detection is performed through lateral displacement changes as a result from the modulation of microbead surface charge or size induced by the adsorption of bioparticles. The extent of the lateral displacement can be correlated to the amount of bioparticles in the sample. Using this bioparticle-on-bead method, changes in lateral shift correlating to the bioparticle concentrations can be sensitively discriminated. The detection of albumin proteins and nano-sized polymer vesicles with a concentration as low as $10 \mathrm{ng} \mathrm{mL}^{-1}(150 \mathrm{pM})$ and $3.75 \mu \mathrm{g} \mathrm{mL}^{-1}$, respectively is demonstrated. This work sets the precedent for sensitive detection and quantification of biological particles via sensitive changes in size or electrostatic interactions of the microbead carrier on DLD. We pushed the boundaries of DLD and applied our model for fluorescent label-free detection of nano-sized proteins and polymer vesicles, which open opportunities for low-cost medical diagnosis, liquid biopsy, and detection of biologically relevant DNA, RNA, exosomes, viruses, and proteins.

\section{Results}

Electrostatic influence on particle-DLD interactions. Electrostatic forces in DLD are non-trivial and can significantly influence particle-DLD interactions $^{21}$ (Fig. 1b). We investigated these effects using a $\times 600$ magnification and high-speed capture of $1000 \mathrm{fps}$, and different particle positions were experimentally tracked and superimposed (Fig. 2a). The DLD segment used for this capture had a gap of $4 \mu \mathrm{m}$ and gradient of $0.75^{\circ}$ resulting in a $D_{c}$ of $700 \mathrm{~nm}$ and the interaction between $1 \mu \mathrm{m}$ particle and the DLD pillar is ensured. The difference between different ionic media is evident in the particle motion and distance between particle positions. The electrostatics force repels the beads from the pillar at low ionic concentration, which displace the beads into a streamline further away from the pillar. The simulations show that small shifts in particle streamlines could drastically change the curvature of motion of particle. We also measured the mean flow velocity of these particles and found that increasing the ionic concentration reduces the average particle flow velocity (Supplementary Fig. 1). This confirms that at lower ionic concentrations, electrostatic interactions shifts the beads into a streamline away from the pillar resulting in an increase in velocity and shift in lateral displacement.

To evaluate the extend of electrostatic lateral shift in $D_{\text {app}}$, a baseline reference curve for DLD device was developed by characterising $D_{\text {app }}$ using DLD-S1 device under control conditions of native poly-dimethylsiloxane (PDMS) surface with $1 \mu \mathrm{m}$ polystyrene (PS) National Institute of Standards and Technology (NIST) beads and $\mathrm{NaCl}$ solutions of different concentrations (Fig. 2b). The curve represents the mean $D_{\text {app }}$ size based on various conditions of separation spectrums (Supplementary Fig. 2).

At $\sim 350 \mu \mathrm{M} \mathrm{NaCl}, D_{\mathrm{app}}=D_{\mathrm{p}}$ where the stipulated particle size is comparable to the $D_{\text {app }}$. NaCl concentrations lower than 350 $\mu \mathrm{M}$ yield a greater $D_{\text {app }}$ due to increase in electrostatic repulsion, whereas higher $\mathrm{NaCl}$ concentrations would mean an increase in surface charge shielding and smaller $D_{\text {app }}$. It is important to note that the size of the particle do not change, rather the changing electrostatic interactions shifts the particle into different streamlines in DLD resulting in sensitive changes in apparent size. Although the actual size of particle does not change, the cause of the smaller $D_{\text {app }}$ influence has not yet been investigated, a likely reason is due to the attraction of particle towards the pillar via hydrophobic interaction when the electrostatic effect is shielded ${ }^{22}$. This is supported by the increase of bead adhesion on pillar at high ionic concentration above 100 $\mathrm{mM}^{23}$. The $D_{\text {app }}$ curve serves as a baseline reference for comparison with various parameters of surface charge, particle surface, and different buffers to be tested and optimized for bioparticle detection.

Optimizing surface charge parameters for DLD separation. Three parameters are used to experimentally investigate the surface charge effects on $D_{\text {app }}$ shifts namely, PDMS device surface charges, bead surface charges, and $\mathrm{pH}$ of the fluid media. Figure 3 summarizes the effects of various parameters on $D_{\text {app }}$ curve plots at different ionic concentrations. Despite large difference in $D_{\text {app }}$ shifts across different parameters, there is minimal difference in bead sizes as observed with transmission electron microscopy (TEM) and dynamic light scattering (DLS) (Supplementary Fig. 3).

Figure 3 shows the measured mean lateral shifts in $D_{\text {app }}$ between various DLD experimental parameters and the reference standard curves of native PDMS, $1 \mu \mathrm{m}$ PS NIST beads, and $\mathrm{NaCl}$ solution. Using the control $D_{\text {app }}$ curve as the reference, the shift in $D_{\text {app }}$ curves in the DLD-S1 can be measured to characterize the influence of these parameters (Supplementary Fig. 4). 
The positive $(+)$ or negative $(-)$ shift of $D_{\text {app }}$ is made relative to the control $D_{\text {app. }}$. The plasma treated surface increases the mean $D_{\text {app }}$ by $+164 \mathrm{~nm}$ compared with native PDMS. Plasma activation increases the number of $\mathrm{SiO}^{-}$surface groups and creates a highly negatively charged PDMS surface with isoelectric point of $\mathrm{pH} 2$ to $\mathrm{pH} 5^{24-26}$. By exposing plasma activated surface to different $\mathrm{pH}$ solutions, the $D_{\mathrm{app}}$ values change dramatically as the different $\mathrm{pH}$ influences the magnitude and ionization of the surface groups ${ }^{27}$. The use of $\mathrm{NaOH}$ ranging from $\mathrm{pH} 9.7$ to 11.5 $(50-3000 \mu \mathrm{M})$ would alter the electrostatic interactions by increasing the mean $D_{\text {app }}$ to $+342 \mathrm{~nm}$ compared with pure native PDMS in $\mathrm{NaCl}$ solution. The use of $\mathrm{HCl}$ on the contrary reduces the electrostatic influence of the highly-charged plasma activated PDMS surface ${ }^{25}$. This is expected as the association of $\mathrm{H}^{+}$to the surface of the DLD device would result in reduction of negatively charged groups, thus reducing electrostatic interactions to $+135 \mathrm{~nm}$ mean $D_{\text {app }}$. It is important to note that the surface charge of plasma-treated PDMS is still negative as it is still beyond its isoelectric point.
Different bead surfaces namely PS-, PS-carboxylated (COOH)-, and poly-allylamine hydrochloride $(\mathrm{PAH})$-coated beads were also tested. Using the same plasma-activated surface, $\mathrm{COOH}$ beads displayed a mean $D_{\text {app }}$ shift of $+167 \mathrm{~nm}$, which is similar to plain PS beads at $+164 \mathrm{~nm}$. Further measurements of colloidal zetapotential suggest similar colloidal stability and potential of -21.4 $\mathrm{mV}$ for PS and $-29.5 \mathrm{mV}$ for PS-COOH in deionised (DI) water. To induce a positively charged bead, the PS-COOH bead was coated with positively charged $\mathrm{PAH}$ which would physically adsorb to the negatively charged bead. The zeta potential measurement shows the PAH coating results in the $+43 \mathrm{mV}$ surface zeta potential in DI water. The beads were flowed into the DLD setup and as expected, the positively charged beads attracted to the negatively charged DLD device surface at the entrance of the reservoir and could not enter the DLD pillar region (Supplementary Fig. 5). Therefore, electrostatic interactions significantly influence particle separation in DLD device and ensuring charge repulsion of particle-DLD surface is necessary.

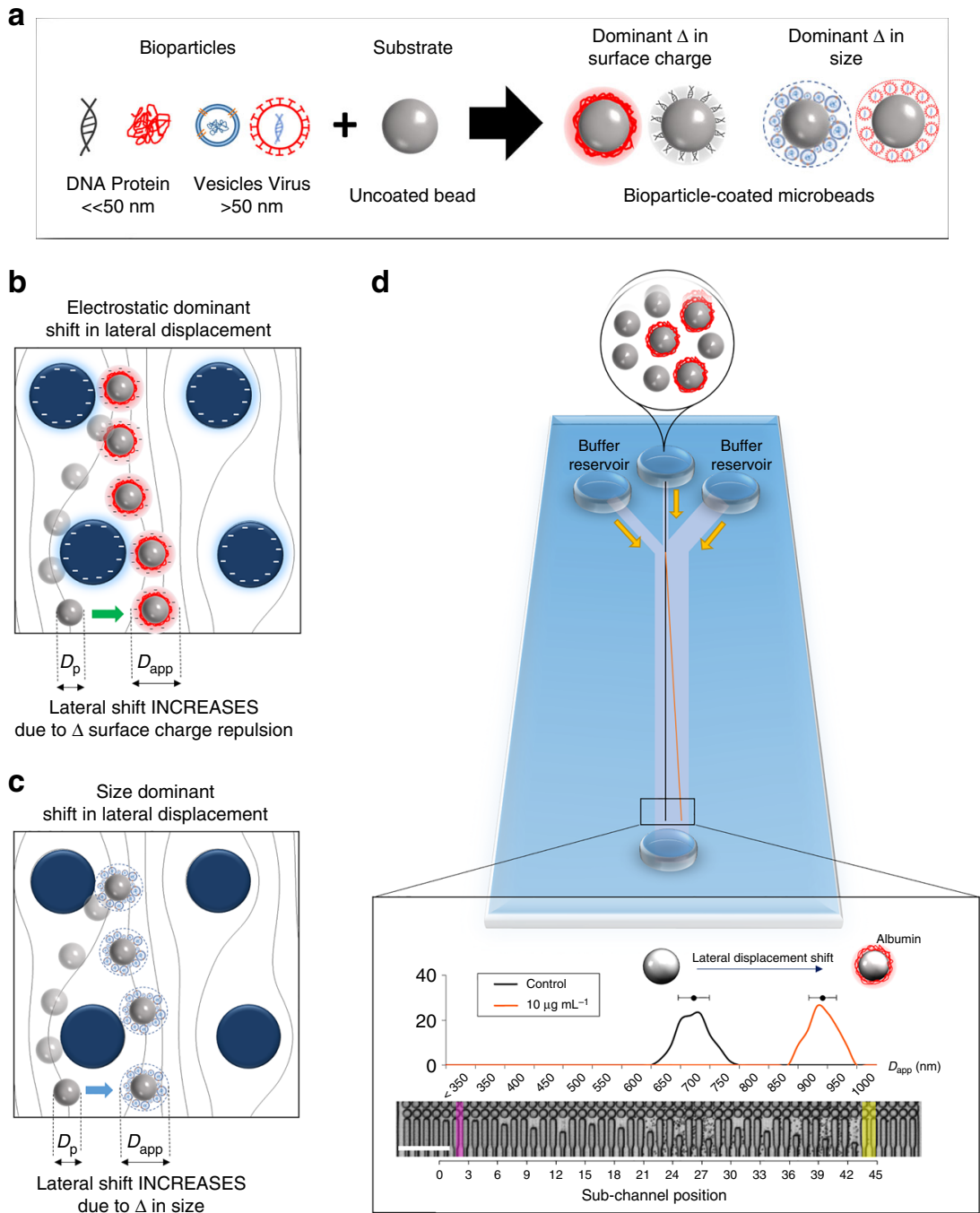

Fig. 1 DLD-based detection of bioparticles using coated micro-bead substrate. a Adhering bioparticles on to the surface of micro-beads causing overall change in surface charge and size of bioparticle-microbead conjugates. Two mechanisms proposed to increase the apparent diameter $\left(D_{\text {app }}\right)$ for detection using $\mathbf{b}$ electrostatic charge repulsion depicted by the negatively charged pillars and bead, and $\mathbf{c}$ size increase of the bioparticle-microbead conjugate. d Shows the DLD device schematics, which can sensitively detect a lateral shift of a $10 \mu \mathrm{g} \mathrm{mL}^{-1}$ albumin coated with a mixture of uncoated $1 \mu \mathrm{m}$ PS-COOH beads. Lateral shifts in the DLD output spectrum can be correlated to the corresponding $D_{\text {app }}$. The black line shows the input position of the microbead sample, magenta band represents where $D_{\text {app }}=350 \mathrm{~nm}(0.35 \mu \mathrm{m})$, and yellow band represents the maximum displaced spectrum of $1000 \mathrm{~nm}(1 \mu \mathrm{m})$. Scale bar is $50 \mu \mathrm{m}$ 
a
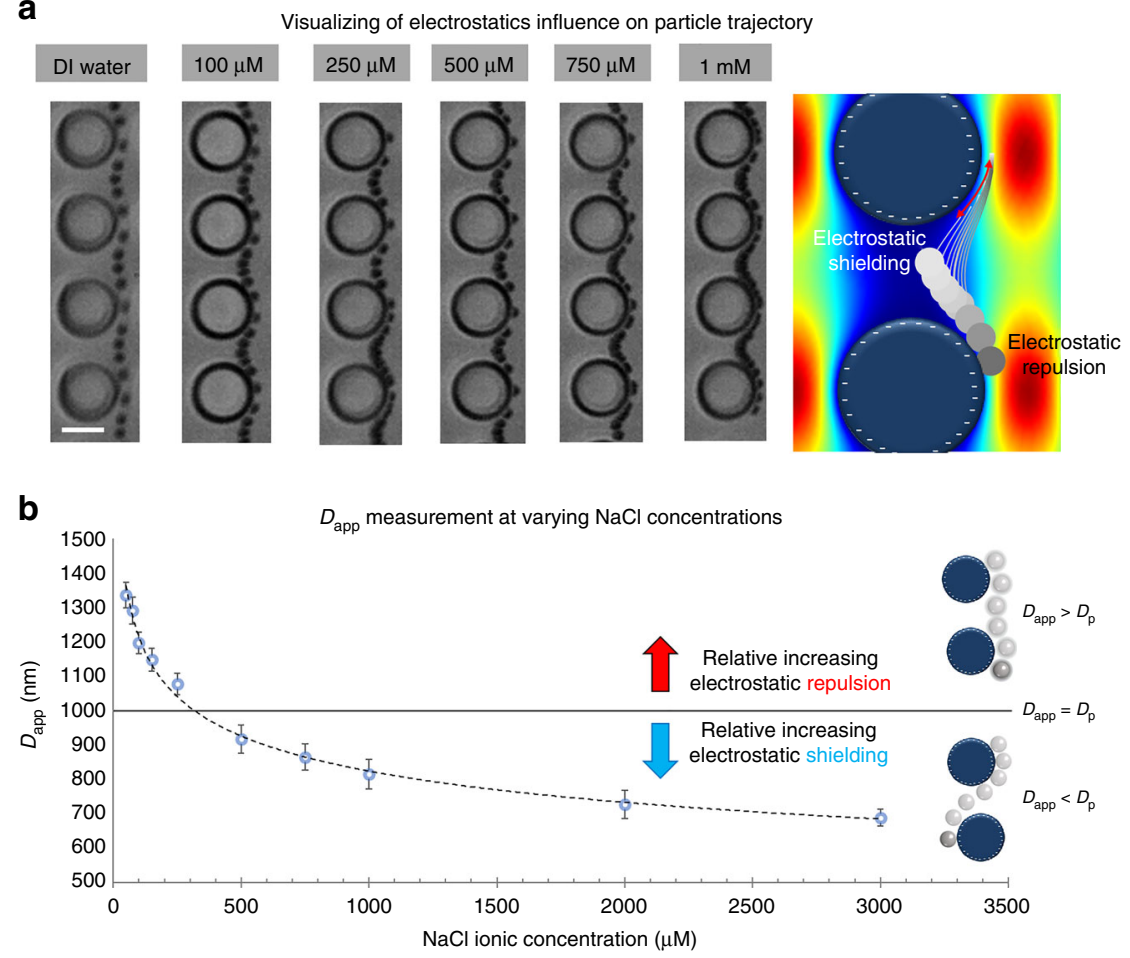

Fig. 2 Visualization of electrostatic dominant lateral shift phenomena. a Shows a tracked motion of $1 \mu \mathrm{m}$ PS beads within a DLD segment with predicted $D_{\text {app }}$ to be $>700 \mathrm{~nm}$ and COMSOL computation of various trajectory taken by a $1 \mu \mathrm{m}$ particle due to shifts in stream lines. Scale bar is $5 \mu \mathrm{m}$. $\mathbf{b} \mathrm{NaCl}$ buffer concentration modulates the electrostatic interactions and thus changes the $D_{\text {app. }}$. A decrease in ionic concentration results in a larger electrostatic repulsion and thus a positive increase in lateral shift where $D_{\mathrm{app}}>D_{\mathrm{p}}$. Conversely, the particle will appear smaller than $D_{\mathrm{p}}$ due to increased electrostatic shielding for higher ionic concentrations. The error bars show the SD from at least 50 sample counts of beads

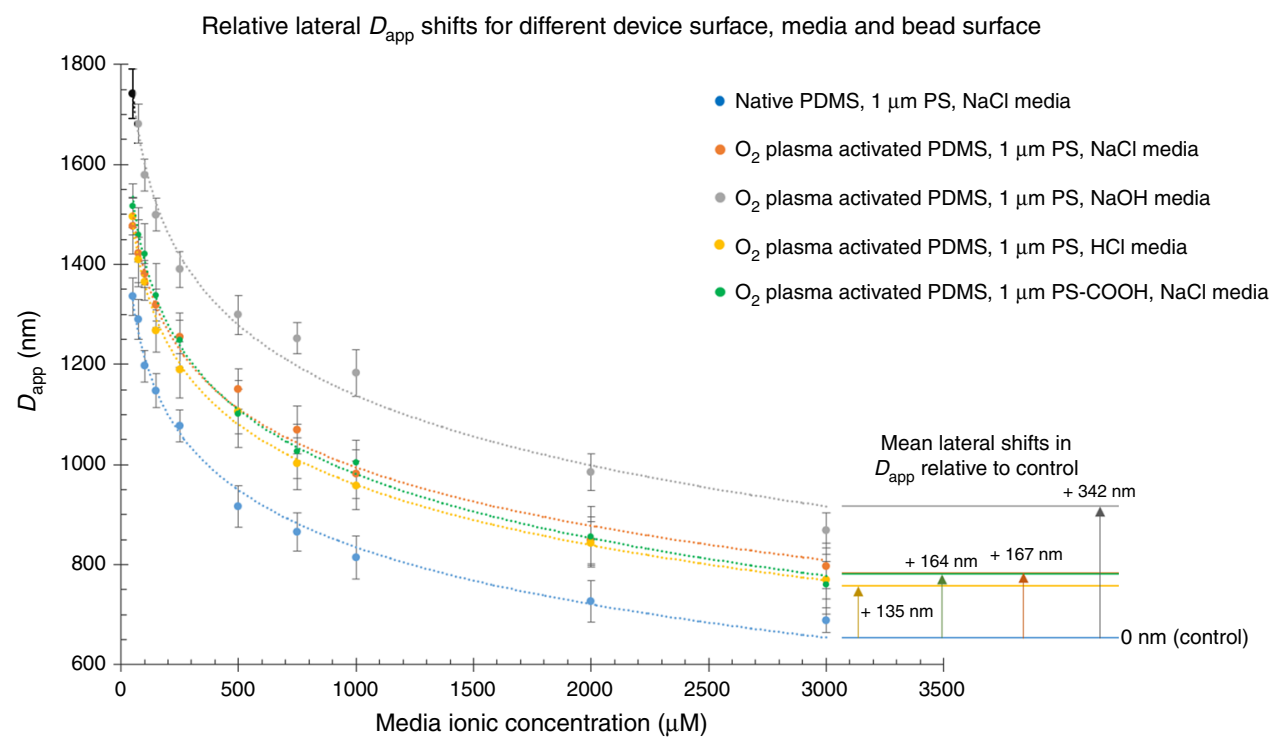

Fig. 3 Parameters governing surface charge influence on the lateral $D_{\text {app }}$ shift. Plot of the relative lateral $D_{\text {app }}$ shift for different device surface, bead surface, and buffer media at different ionic concentrations. The shift is calculated relative to native PDMS control. A positive shift would mean an increase in $D_{\text {app }}$ across all ionic concentration levels. Each data point was plotted based on at least 50 sample counts and the error bar represent the SD of the sample $D_{\text {app }}$

Florescent label-free detection of protein coated beads. A protein-coated bead is predicted to change the surface properties of the bead substrate which will result in a change in lateral $D_{\text {app }}$ shift. The amount of $D_{\text {app }}$ shift is hypothesized to correlate to the amount of proteins on the bead surface. Native albumin protein has a hydrodynamic radius of $3.7 \mathrm{~nm}$ and a protein coated bead would increase the theoretical hydrodynamic size of the bead by at most $10 \mathrm{~nm}^{28}$. This size difference is lower than the resolution of our device (Supplementary Note 1 and Supplementary Fig. 6). However, using the particle-pillar electrostatic effects, these differences could be easily detected in the DLD setup by quantifying the changes in the $D_{\text {app }}$ of beads. The DLD-S2 


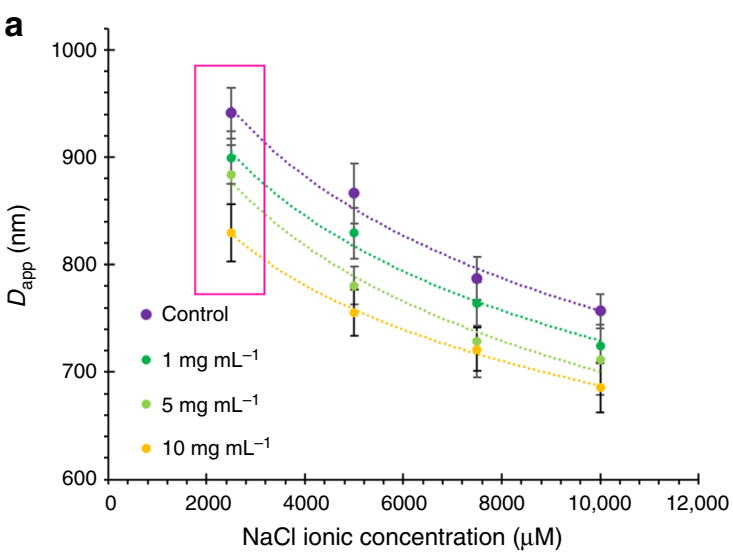

C

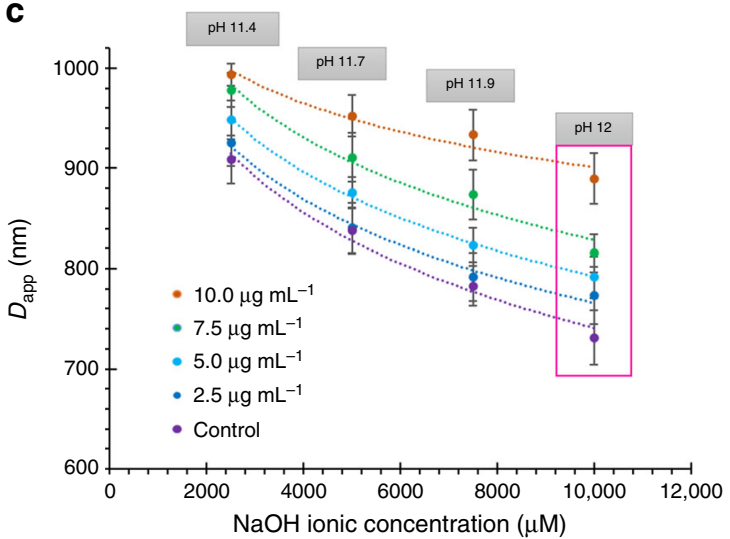

b

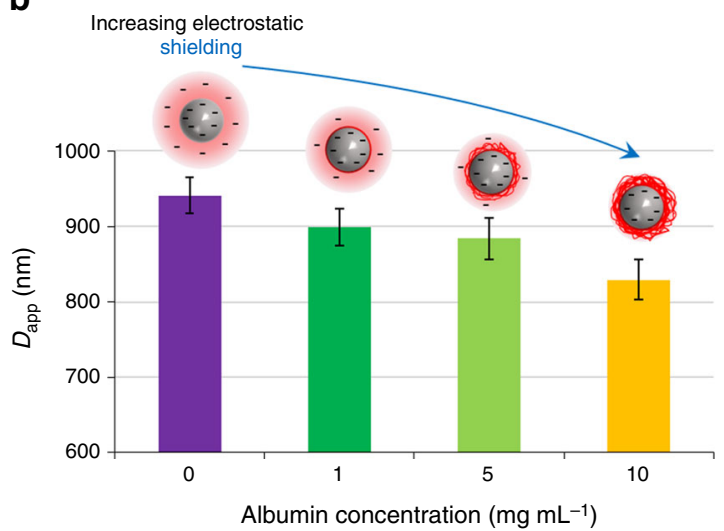

d

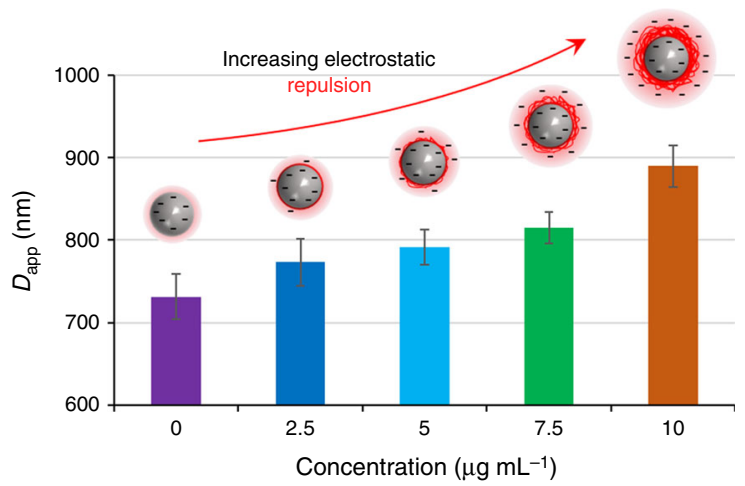

Fig. 4 Optimizing albumin concentration detection range and electrostatic interactions. a Shows detection of proteins in the $\mathrm{mg} \mathrm{mL}^{-1}$ range using varying $\mathrm{NaCl}$ concentrations as the media. The greatest difference in mean lateral $D_{\text {app }}$ shifts is highlighted in the magenta box and shown in $\mathbf{b}$ where increasing protein concentration shields the surface charges on the beads. c Using $\mathrm{NaOH}$ alkaline solution, detection of proteins within the $\mu \mathrm{gg} \mathrm{ml}^{-1}$ range was performed and the greatest difference of the mean lateral shifts is shown in $\mathrm{pH} 12 \mathrm{NaOH}$ media (within the magenta box). d Shows the $D_{\text {app }}$ of different coated beads in a NaOH pH 12 media. All data point comprises of the distribution of at least 50 beads with the error bar representing the SD of the calculated $D_{\mathrm{app}}$

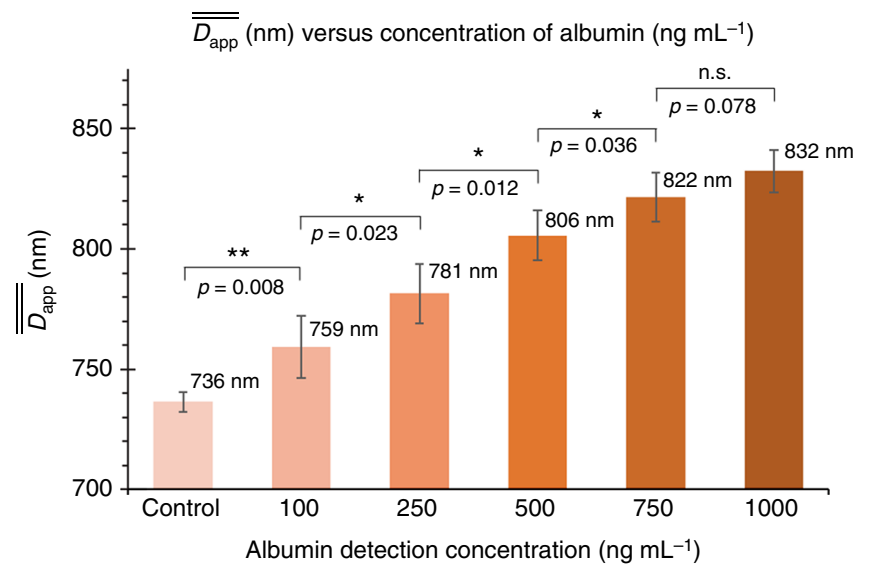

Fig. 5 The detection of albumin in the $\mathrm{ng} \mathrm{mL}^{-1}$ range. The bar graph represents the different $\overline{\overline{D_{\text {app }}}}$, mean of mean $D_{\text {app }}$, for various protein concentration. The control beads were not exposed to albumin, while the albumin concentrations for detection were ranged from 100 to $1000 \mathrm{ng} \mathrm{mL}^{-1}$. Four sets of experiments were independently performed and the mean of mean $D_{\text {app }}$ values were analysed $(n=4)$ with SD as the error bars. Independent two-sample $t$-test is used for the statistical analysis where ${ }^{\star} p<0.05,{ }^{* \star} p<0.01$, and $n . s$. $=$ not significant device has a higher theoretical resolution limit of $\sim 10 \mathrm{~nm}$ and would be used in this study to increase the sensitivity of electrostatic-induced interaction.

PS microbeads were suspended in different concentrations of albumin solutions to form an albumin coat on the bead with DI water as the adsorption media. The beads suspended in proteins of concentration range from 1 to $10.0 \mathrm{mg} \mathrm{mL}^{-1}$ showed decreasing $D_{\text {app }}$ (Fig. $4 \mathrm{a}$ ). The zeta-potential of the beads in $\mathrm{NaCl}$ solutions was measured and it was found that the surface charges were shielded (Supplementary Fig. 7). This result corresponds to a decrease in mean $D_{\text {app }}$ for an albumin coated bead since electrostatic charges are muted due to the albumin coat in $\mathrm{NaCl}$ solution. The use of $\mathrm{NaCl}$ in the range of $2000 \mathrm{mM}$ elicited the largest difference between the different protein concentrations (Fig. $4 \mathrm{~b}$ and Supplementary Fig. 8a).

We tested the effects of using alkaline $\mathrm{pH}$ solutions on the increase in electrostatic interactions and detection sensitivity. At high $\mathrm{pH}$, the albumin protein would unfold and the charge density would have increased significantly due to disassociation of $\mathrm{H}^{+}$charged groups from the albumin ${ }^{29}$. The impact of $\mathrm{pH}$ of medium on protein-coated beads' apparent diameter as compared to the $D_{\text {app }}$ in $\mathrm{NaCl}$ solution showed a significant increase of approximately 400 -fold in sensitivity of protein coat detection (from $1 \mathrm{mg} \mathrm{mL}^{-1}$ to $2.5 \mu \mathrm{g} \mathrm{mL}^{-1}$ ). Figure $4 \mathrm{c}$ shows the separation of $2.5-10 \mu \mathrm{g} \mathrm{mL}^{-1}$ albumin protein-coated $\mathrm{COOH}$ beads in alkaline $\mathrm{NaOH}$ solution of concentration $2.5-10.0 \mathrm{mM}$ 
( $\mathrm{pH} 11.4-12)$. At $2.5 \mu \mathrm{g} \mathrm{mL} \mathrm{L}^{-1}$ of albumin, the protein coat formed on $\mathrm{COOH}$ beads have a mean $D_{\text {app }}$ difference of $18 \mathrm{~nm}$. However, at $5.0 \mu \mathrm{g} \mathrm{mL}^{-1}$, the mean difference has increased to 44 $\mathrm{nm}$, which shows difference in peaks across all alkaline $\mathrm{pH}$. The most significant observable difference is at $10 \mu \mathrm{g} \mathrm{mL}^{-1}$ protein concentration where there is a relatively large increase of $127 \mathrm{~nm}$ in $D_{\text {app }}$ of coated beads compared to the non-coated beads in alkaline $\mathrm{pH} 12 \mathrm{NaOH}$ solution (Fig. 4d and Supplementary Fig. $8 \mathrm{~b}$ ). On the contrary, low $\mathrm{pH}$ solutions were tested and it was found that even at $1 \mathrm{mM} \mathrm{HCl}$, the albumin-coated beads started to stick non-specifically to the device (Supplementary Fig. 9). This is because the charges on the beads have changed from negative to positive for $\mathrm{pH}$ 4. This also indirectly confirms the presence of albumin on the beads as the $\mathrm{pI}$ of albumin is $\sim 4.7^{30}$. This charge inversion facilitates the electrostatic attraction force between the positively charged beads and surface of negatively charged microchannels.

An optimized adsorption albumin protocol was performed using pH 5.5 2-morpholinoethanesulfonic acid (MES) buffer and lower concentrations of the beads. This, combined with the use of $\mathrm{pH} 12 \mathrm{NaOH}$ solution for DLD separation, results in a significant decrease in the limit of albumin detection concentration (Fig. 5 and Supplementary Fig. 10). Four independent sets of samples were tested using four PDMS devices and the mean $D_{\text {app }}$ of the four samples were averaged and plotted as $\overline{D_{\text {app }}}$ in Fig. 5 for various concentration of protein adsorption ranging from 100 to $1000 \mathrm{ng} \mathrm{mL}^{-1}$ (Supplementary Fig. 11). The results showed that we could detect as low as $100 \mathrm{ng} \mathrm{mL}^{-1}$ of albumin, which corresponds to approximately $1.5 \mathrm{nM}$ of albumin using this labelfree approach. The $\overline{\overline{D_{\text {app }}}}$ of $750 \mathrm{ng} \mathrm{mL}^{-1}$ and $1000 \mathrm{ng} \mathrm{mL}^{-1}$ were 822 and $832 \mathrm{~nm}$, respectively, which did not yield a significant difference of a $10 \mathrm{~nm} D_{\text {app }}$ change, which is at the limits of resolution for the DLD-S2 device.

To ensure specific binding to proteins and higher detection sensitivity, beads conjugated with human serum albumin (HSA) antibody were used to detect the presence of HSA (Fig. 6a). The binding of HSA to the antibody was confirmed using fluorescence labelled secondary antibody binding (Supplementary Fig. 12). The limits of detection of HSA using antibody testing were found to be 10 times more sensitive, ranging from 10 to $75 \mathrm{ng} \mathrm{mL}^{-1}$, than the physical adsorption of albumin on $1 \mu \mathrm{m}$ bead. Similarly, $n=3$ independent sets of readings were performed using three PDMS device and the corresponding $\overline{D_{\mathrm{app}}}$ detection range for $10-75 \mathrm{ng}$ $\mathrm{mL}^{-1}$ of HSA protein were $771-842 \mathrm{~nm}$, respectively (Fig. $6 \mathrm{~b}$ and Supplementary Fig. 13). The $\overline{\overline{D_{\text {app }}}}$ of $25 \mathrm{ng} \mathrm{mL}^{-1}$ of HSA is not statistically significant compared with $10 \mathrm{ng} \mathrm{mL}^{-1}$ as the $\overline{\overline{D_{\text {app }}}}$ difference is $\sim 10 \mathrm{~nm}$, which is close to the LOD of the DLD-S2 device. The detection was performed under $\mathrm{NaOH} \mathrm{pH} 12$ for comparison with earlier studies on albumin adsorption to bead. The use of antibody-conjugated beads increases the specificity of protein binding and sensitivity of detection to as low as $150 \mathrm{pM}$. This method of protein detection does not use fluorescence label, secondary antibody or nanoparticle aggregation methods and is comparable to existing label-free protein detection such as SERS, SPR, or microcantilevers ${ }^{31,32}$.

Fluorescence label-free detection of vesicle on DLD. Extracellular vesicles (EVs) have importance in intercellular communication, regeneration, and transport. ${ }^{33-37}$ Furthermore, integral proteins present in the membrane of EVs have significant roles in mediating these communications and have emerged as biomarkers for exosomes in various pathological and normal conditions. $^{38-43}$ Thus, the detection of EVs and its membrane proteins is crucial for disease diagnosis. Owing to advantages of mechanical stability and membrane tunability, polymer vesicles a

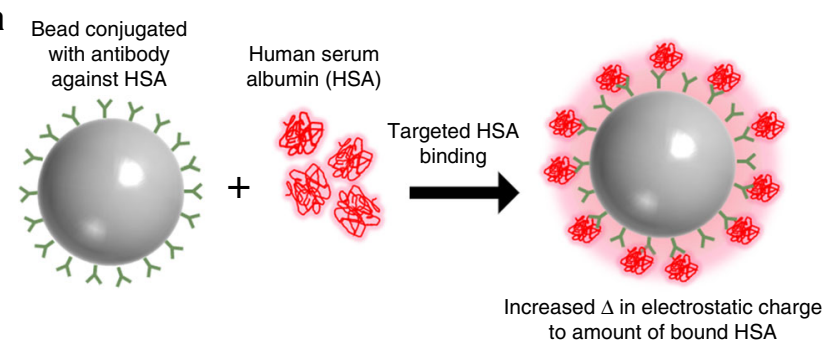

b

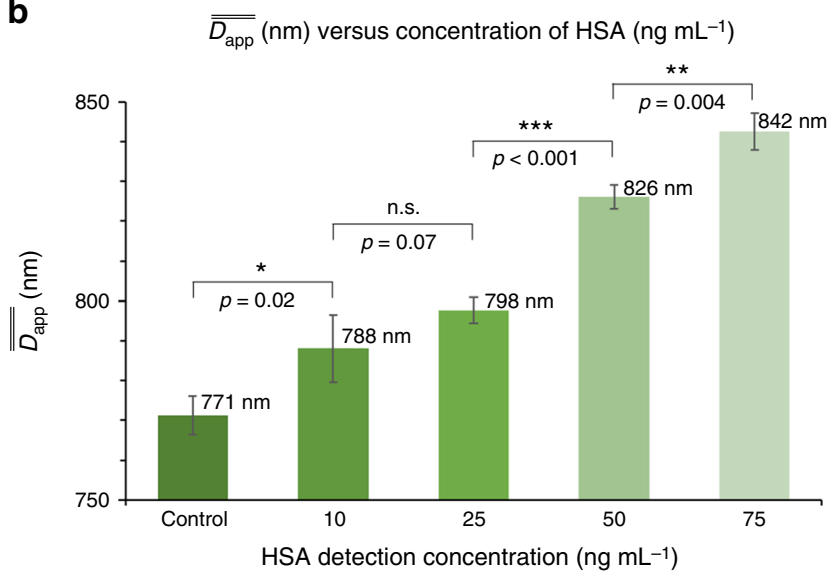

Fig. 6 Detection of HSA using antibody coated beads. a Schematics showing the detection of human serum albumin with the capture of antibody for higher detection sensitivity. $\mathbf{b}$ Three sets of readings were performed for the detection of HSA from 10 to $75 \mathrm{ng} \mathrm{mL}^{-1}(n=3) . \overline{\overline{D_{\text {app }}}}$ represents the mean of mean $D_{\text {app }}$ for the three data sets with SD as the error bars (Supplementary Fig. 13). Independent two-sample $t$-test is used for the statistical analysis. Where ${ }^{\star} p<0.05,{ }^{\star \star} p<0.01,{ }^{\star \star \star} p<0.001$, and n.s. $=$ not significant

were chosen over lipid vesicles for incorporating the membrane proteins for the current study. ${ }^{44-46}$ BD21 vesicles with a TEM size range of $132 \pm 31 \mathrm{~nm}$ were prepared and characterised for size, shape, and surface charge (Methods and Supplementary Fig. 14).

Similar to protein detection, these nanovesicles were adsorbed onto the surface of the beads and the detection range was found to be between 0.32 and $2.5 \mathrm{mg} \mathrm{mL}^{-1}$ under $0.1 \times$ phosphate buffered saline (PBS) media (Supplementary Figs. 14 and 15, and Supplementary Note 2). To confirm that the lateral displacement is dominantly driven by the size increase instead of charge, beads were coated with dissolved vesicles. The dissolved vesicles were prepared via detergent dissolution which resulted in the size of $\sim$ $8 \mathrm{~nm}$ and similar surface charge compared with the undissolved vesicle. It was observed that the apparent diameter of the beads coated with dissolved vesicle is similar to the uncoated beads (Supplementary Fig. 16).

To further enhance the detection specificity and sensitivity of nano-vesicles, primary antibodies conjugated beads were used to bind to polymer nano-vesicles reconstituted with Aquaporin-1 proteins (Aqp1). As most EVs contain surface markers and proteins, Aqp1 was reconstituted onto polymer vesicles to demonstrate the detection by antibody coated beads in DLD device based on change in bead size. Aqp1 is a membrane pore protein which allows the permeability of water and was used as a model protein for detection of nano-vesicles. ${ }^{47,48}$ The incorporation of Aqp1 membrane protein to vesicles was done by widely used detergent-mediated reconstitution method that involves vesicle dissolution using detergent and protein reconstitution with removing the detergent using biobeads (Methods). It is 

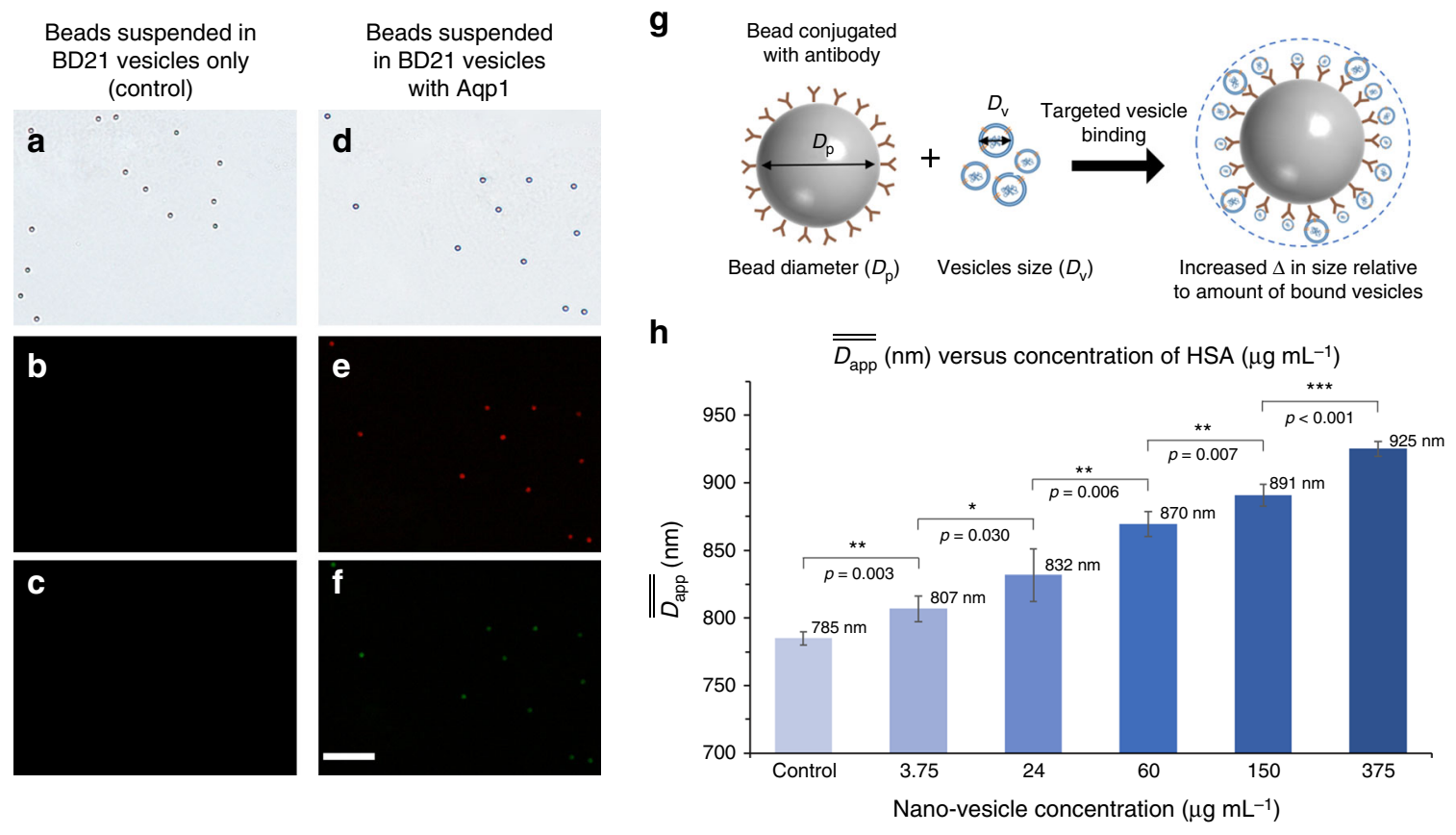

Fig. 7 Vesicle detection using antibody immobilised beads. PS-COOH beads $(1 \mu \mathrm{m})$ conjugated with Aquaporin-1 (Aqp1) antibody incubated with BD21 vesicles without Aqp1 protein showing no binding of vesicles a-c. The specific binding of BD21 vesicles containing Aqp1 protein on the anti-Aqp1-beads as confirmed by fluorescence from RBOE dye in vesicles in e. Fluorescence from Alexa-fluor 488-labelled secondary antibody further confirmed the presence of Aqp1 in vesicles bound to the anti-Aqp1-beads $\mathbf{f}$. Scale bar is $10 \mu \mathrm{m}$. $\mathbf{g}$ Schematics showing the detection based on the change in size due to the binding of vesicles onto the antibody-conjugated beads. The buffer media used here is $0.1 \times$ PBS solution. $\mathbf{h}$ The detection of vesicle concentrations of 3.75-375 $\mu \mathrm{g} \mathrm{mL}^{-1}$ was performed with four sets of samples $(n=4)$ with SD as the error bars. Independent two-sample $t$-test is used for the statistical analysis where ${ }^{\star} p<0.05,{ }^{* \star} p<0.01$, and ${ }^{* \star *} p<0.001$

important to note that the reconstituted vesicles are smaller compared to the original size of vesicles which could be due to a faster rate of detergent removal (Supplementary Fig. 17) ${ }^{49}$. The concentration of reconstituted Aqp1 vesicles were then assessed by Bicinchoninic Acid (BCA) assay (Supplementary Fig. 18), whereas its functionality was shown by the shrinking of Aqp1 vesicles upon gradual exposure to hyperosmotic sucrose solution compared with vesicles without Aqp1 (Supplementary Table 1).

The binding specificity of the $\mathrm{BD} 21$ nano-vesicles to the antibody-conjugated beads was confirmed using fluorescent probes (Fig. 7a-f). Interestingly, the DLD vesicle detection through the antibody-based capture of BD21 vesicles showed a 90-fold increase in limits of detection in comparison with the DLD detection with physical adsorption on beads from 0.33 $\mathrm{mg} \mathrm{mL}^{-1}$ down to $3.75 \mu \mathrm{g} \mathrm{mL}^{-1}$ (Fig. 7 and Supplementary Fig. 14). Four sets of experiments were performed using four DLD-S2 devices to acquire the data and the corresponding analysis (Supplementary Fig. 19). The detection range of these nano-vesicles now span two orders of magnitude from 3.75 to $375 \mu \mathrm{g} \mathrm{mL}^{-1}$ with a $\overline{\overline{D_{\text {app }}}}$ ranging from 807 to $925 \mathrm{~nm}$ under $0.1 \times$ PBS buffer (Fig. 7). At this ionic concentration, the electrostatic interactions are muted and changes in the bead mean $D_{\text {app }}$ size is correlated to the increase in the amount of vesicles bound to the antibody-conjugated bead. At low vesicle concentrations, the sparsely bound vesicles hardly change the average diameter of the bead, whereas at $375 \mu \mathrm{g} \mathrm{mL}^{-1}$, the size of the bead increases by $140 \mathrm{~nm}$ compared with the control. This concentration is within the detection range of some exosomes isolated from physiological conditions, which can vary from several $\mu \mathrm{g} \mathrm{mL}^{-150,51}$ down to $\mathrm{g} \mathrm{mL}^{-152}$ depending on the source of the exosome (plasma or serum), its cells type, pathological status (healthy or diseased), and purpose.

\section{Discussion}

Using albumin and polymer vesicle as proof of concept, we demonstrated a fluorescent label-free method for detection of nano-sized albumin proteins and vesicles using a PDMS DLD pillar array with micrometer-sized features. The advantages of this method are multi-fold. Fabrication of such a pillar array with micrometer-sized features is much less challenging as compared with the devices that require nanofabrication. The fluid flow does not require high pressures and the detection can be easily performed using standard bright-field bench-top microscopes ${ }^{18}$. The attachment of bioparticles on microbeads also significantly reduces the effect of diffusion. Specific ligands can be immobilized on different microbeads to capture different bioparticles of interest. Moreover, the electrostatic interactions between surface proteins and DLD pillars could be modulated in real-time using different buffer ionic concentrations and the resultant lateral shift of the microbeads can be used to detect different amounts of proteins ${ }^{21}$. The detection of HSA proteins on beads via electrostatics dominant change in DLD has a LOD of $10 \mathrm{ng} \mathrm{mL}^{-1}$, whereas detection of polymer vesicles based on particle size change has a detection limit of $3.75 \mu \mathrm{g} \mathrm{mL}^{-1}$. The vesicle membrane protein detection by antibody-coated beads in DLD device can be further extended to specific detection of EVs such as exosomes based on their respective membrane proteins.

We have demonstrated that the fluorescence label-free method for nano-sized bioparticle detection is inexpensive, sensitive and only requires a standard laboratory microscope for the measurement of bead lateral position in the DLD PDMS device. Furthermore, with a $50 \mathrm{fps}$ capture framerate, it is possible to integrate the detection onto portable imaging solutions and hold great potential for use in point of care diagnostics. 


\section{Methods}

Device design. Using Eq. 1, two DLD devices were designed with incremental step resolution (Supplementary Fig. 6). DLD System 1 (DLD-S1) was designed for highdynamic range of $D_{\mathrm{app}}$ and DLD System 2 (DLD-S2) was designed for high resolution displacement. DLD-S1 has a $100 \mathrm{~nm} D_{\text {app }}$ increment measurement and DLD-S2 is $50 \mathrm{~nm}$. The two systems also have different sensitivity for separation of $1 \mu \mathrm{m}$ bead substrates in ionic buffer. DLD system 1 (DLD-S1) has dynamic range from $1 \mu \mathrm{M}$ to $3 \mathrm{mM}$, whereas DLD system 2 (DLD-S2) has greater range of 0.5-150 mM. These DLD devices have 14 DLD segments connected in series with gap sizes fixed at $4 \mu \mathrm{m}$ for DLD-S1 and $2 \mu \mathrm{m}$ for DLD-S2. This results in a particle size resolvable quasi-resolution of $34 \mathrm{~nm}$ for DLD-S1 and $17 \mathrm{~nm}$ for DLD-S2. The input sample stream is sandwiched by two buffer streams to a width of a single input channel.

Electrostatic and size dominant separation in DLD. DLD is a robust label-free microfluidics particle separation technique pioneered by Huang et $\mathrm{al}^{13}$. This technique uses pillar array with certain gap which is tilted in an angle and generates unique number of streamline between the gap that can laterally displace particle above the critical diameter. This $D_{c}$ of the separation is influenced by the gap between pillars and the row shift fraction. Davis et al. ${ }^{16,53}$ proposed an empirical formula for DLD array. ${ }^{54}$

$$
D_{\mathrm{c}}=1.4 G \varepsilon^{0.48}
$$

Where $G$ is the gap or pore size between pillars and $\varepsilon$ is the row shift fraction $(\varepsilon=\tan \theta)$ when $\theta$ is the angle of the gradient. Particles larger than this $D_{c}$ will displaced laterally, whereas particles smaller than $D_{c}$ flow through the array without any lateral displacement. Therefore, for lateral displacement to occur, the particle diameter $\left(D_{\mathrm{p}}\right)$ must be greater than $D_{\mathrm{c}}$.

Although Eq. 1 determines the particle physical size for separation, it does not account for the influence of electrostatic forces on the particle cut-off size in DLD. We previously determined that electrostatic force effects on DLD separation is non-trivial even for particles as large as $1 \mu \mathrm{m}^{21}$. Using our DLD device, we can measure the effect of electrostatic forces by changes in the apparent size of the particles (Supplementary Fig. 20).

$$
D_{\text {app }}=D_{\mathrm{F}-\mathrm{EDL}}+D_{\mathrm{p}}
$$

The $D_{\mathrm{F}-\mathrm{EDL}}$ term describes the additional displacement of the particle due to the summation of hydrodynamic and electrostatic forces acting between the DLD pillar and particle. When $D_{\mathrm{F}-\mathrm{EDL}}$ is positive $\left(D_{\mathrm{app}}>D_{\mathrm{p}}\right)$, the particle appears larger than it physically is in the DLD device and has a greater lateral displacement (Fig. 1). Interestingly, the converse is possible when $D_{\mathrm{F}-\mathrm{EDL}}$ is negative $\left(D_{\mathrm{app}}<D_{\mathrm{p}}\right)$, and the particle reduces its apparent size resulting in reduced lateral displacement. This does not mean that the electrostatic force becomes attractive, rather the surface charges on pillar and particle surface are being shielded such that the baseline repulsive force in a stable colloidal system (when $D_{\mathrm{app}}=D_{\mathrm{p}}$ ) is reduced. $D_{\mathrm{F}-\mathrm{EDL}} \mathrm{can}$ be approximated from the following equation,

$$
\mathbf{F}_{\mathrm{F}-\mathrm{EDL}}=\frac{2 \pi \lambda_{\mathrm{D}} R}{\varepsilon_{0} \varepsilon}\left(\left(\sigma_{\mathrm{p}}^{2}+\sigma_{\mathrm{s}}^{2}\right) \mathrm{e}^{-2 \mathrm{D}_{\mathrm{F}-\mathrm{EDL}} / \lambda_{\mathrm{D}}}+2 \sigma_{\mathrm{p}} \sigma_{\mathrm{s}} \mathrm{e}^{-\mathrm{D}_{\mathrm{F}-\mathrm{EDL}} / \lambda_{\mathrm{D}}}\right)
$$

in which $\sigma_{\mathrm{p}}$ is particle surface charge, $\sigma_{\mathrm{s}}$ is device surface charge, and $\lambda_{\mathrm{D}}$ is the debye length of the solution. This Debye length $\left(\lambda_{\mathrm{D}}\right)$ depends on the charge $(z)$ and ionic concentration $(c)$, temperature $(T)$, Boltzmann constant $k_{\mathrm{b}}$, electron charge $(e)$ and Avogadro number $\left(N_{\mathrm{A}}\right)$

$$
\lambda_{\mathrm{D}}=\left[\frac{N_{\mathrm{A}} e^{2}}{\varepsilon \varepsilon_{0} k_{\mathrm{b}} T} \sum_{i} z_{i}^{2} c_{i}^{\infty}\right]^{-1 / 2}
$$

It is predicted from the equations that as ionic concentrations of solution decreases, the electrostatic double layer would increase, suggesting greater electrostatic effects from repulsive surface ${ }^{22}$. This increase in repulsive force virtually increase the diameter $\left(D_{\mathrm{p}}\right)$ of the particle by the electrostatics double layer force $\left(D_{\mathrm{F}-\mathrm{EDL}}\right)$ results in greater lateral displacement of the particle. Fluid flow velocities do affect the separation but it is not very significant and would require increase in excess of 100-fold before there can be an observable effect. Thus, the electrostatic force interaction on particles in DLD can be primarily influence by these three factors-surface charges on the device, particle, and ionic concentration of media ${ }^{55}$.

Therefore, this electrostatic-based displacement can be used for detection of nano-sized biomolecules such as protein or DNA on microbeads, as the presence of biomolecules coat changes the overall surface charge of the microbeads, and hence the electrostatics force and lateral displacement in sensitive DLD.

In contrast, the size-based change is dominant for larger bioparticles coat such as vesicles. The adsorption of the vesicles with a diameter $\left(D_{\mathrm{v}}\right)$ of $50-200 \mathrm{~nm}$ to the microbead surface increases the overall size of the bead from a diameter $\left(D_{\mathrm{p}}\right)$ of 1 $\mu \mathrm{m}$ to $D_{\text {app }}$ of $\sim 1.05-1.4 \mu \mathrm{m}$. It is hypothesized that the $D_{\text {app }}$ is increased as the amount of adsorbed vesicles increases. At lower vesicle concentration, the increase in $D_{\text {app }}$ is small due to random adsorption of small amount of vesicles on beads, whereas at higher concentration when the bead surface is fully adsorbed with the vesicles, the $D_{\text {app }}$ reaches saturation, and hence plateaus off. The usage of antibody specific to the membrane protein increases the sensitivity of the vesicle binding, and hence results in lower LOD of the vesicles.

Device fabrication. Briefly, SU-8 2005 (MicroChem, USA) was used to develop the DLD device negative mould on a 4 -inch silicon wafer at a height of $3 \mu \mathrm{m}$. The SU-8 was patterned using a hard chrome glass mask (Infinite Graphics, Singapore) on a SUSS-MA8 lithography mask aligner. The final device was fabricated using PDMS cured on the silicon SU-8 mould. The input and output holes were punched and the PDMS device was bonded onto a glass slide using a oxygen plasma treatment for $2 \mathrm{~min}$ in the March PX-250 plasma machine. All devices used in this work were fabricated from the same mould to ensure consistency in results.

Sample and buffer solutions. Three types of bead samples were used: $1 \mu \mathrm{m}$ NIST PS beads (Bangslab NT15N, USA), $1 \mu \mathrm{m}$ amine beads (bangslab PA03N, USA), and $1 \mu \mathrm{m}$ carboxylated beads (Polyscience 17458, USA). These beads were subsequently diluted to the required concentration of $0.1 \%(\mathrm{w} / \mathrm{v})$ for all separation experiment Sodium chloride (Sigma S5150, Singapore), sodium hydroxide (Sigma S2770), and hydrogen chloride (Sigma H9892) were prepared as a stock solution of $1 \mathrm{M}$. Nonionic Pluronic F-127 (Sigma P2443) was prepared at 1\% (w/v), whereas albumin solution (Sigma A9576) was purchased as $30 \%(\mathrm{v} / \mathrm{v})$ stock solution. The $50 \mathrm{mM}$ MES buffer $\mathrm{pH} 5$ solution was prepared for the optimized protein adsorption on beads. The $1 \times$ PBS solution (Thermofisher 10010023) was used as the stock PBS solution for vesicle detection. All solutions were diluted subsequently in 18.2 $\mathrm{MOhm} \mathrm{cm}$ Millipore ultra-pure DI water to the required concentration.

Protein physical adsorption on beads. Total of $3 \mu \mathrm{L}$ of $2.64 \%(\mathrm{w} / \mathrm{v})$ carboxylated beads were put into $1 \mathrm{~mL}$ of albumin solution with concentration of $1,0.5$, and 0.1 $\mathrm{mg} \mathrm{ml}^{-1}$, and $10,7.5,5$, and $2.5 \mu \mathrm{g} \mathrm{mL}^{-1}$, and incubated for $15 \mathrm{~min}$ at room temperature with DI water as a buffer for the physical adsorption of albumin to the beads. Subsequently, the beads were washed with centrifugation for three times at 6000 r.p.m. for $3 \mathrm{~min}$ each, to get rid of the remaining unabsorbed albumin in the solution. The beads then were diluted to $15 \mu \mathrm{L}$ for the experiment. The PAH (Sigma 283223) coating were performed by putting $3 \mu \mathrm{L}$ beads to $0.01 \%$ (w/v) PAH in $0.5 \mathrm{M} \mathrm{NaCl}$ buffer for $5 \mathrm{~min}$ and the solution were washed $3 \times$ to remove unabsorbed PAH solution. The optimized protein adsorption for more sensitive detection was performed using MES buffer and smaller volume of beads. Total of $0.5 \mu \mathrm{L}$ of $2.64 \%(\mathrm{w} / \mathrm{v})$ carboxylated beads were put into $1 \mathrm{~mL}$ of albumin solution in $50 \mathrm{mM}$ MES buffer at $\mathrm{pH} 5.5$ with concentration of $1,0.75,0.5,0.25$, and $0.1 \mu \mathrm{g} \mathrm{mL}$ -1 , and incubated for $1 \mathrm{~h}$ at room temperature for the physical adsorption of albumin to the beads. Subsequently, the beads were washed with centrifugation for three times at 6000 r.p.m. for $3 \mathrm{~min}$ each, to get rid of the remaining unabsorbed albumin in the solution. The beads then were diluted to $3 \mu \mathrm{L}$ for the experiment.

Antibody against HSA conjugation on beads. Polyclonal rabbit anti-HSA (Abcam, ab34856) was diluted $80 \times$ and conjugated on $1 \mu \mathrm{m}$ PS-COOH beads surface via $N$-(3-dimethylaminopropyl)- $N$-ethylcarbodiimide hydrochloride (EDC, Sigma Singapore E7750) and $N$-hydroxysuccinimide (NHS, Sigma Singapore 130672) coupling. Briefly, EDC and NHS was added to PS-COOH beads to activate the carboxyl groups and mixed under vortex for $1 \mathrm{~h}$ at 1650 r.p.m., at $4{ }^{\circ} \mathrm{C}$. After activation, the beads were washed three times by centrifugation at 6000 r.p.m. for 5 mins. Before adding the antibody, the bead solution was subjected to probe sonication for $1 \mathrm{~min}$, to ensure uniform dispersion of the beads. The antibodybeads solution was incubated for $3 \mathrm{~h}$ at 1650 r.p.m. vortexing at $4{ }^{\circ} \mathrm{C}$.

Antibody-conjugated beads-based detection of HSA on DLD. The conjugated beads were mixed with different concentration of HSA (Abcam) of $0.075,0.05$, 0.025 , and $0.01 \mu \mathrm{g} \mathrm{mL}^{-1}$ for $1 \mathrm{~h}$ at room temperature and washed by centrifugation at 6000 r.p.m. for $3 \mathrm{~min}$ before putting in the sample inlet for DLD separation with $10 \mathrm{mM} \mathrm{NaOH}$ buffer. The device used was plasma-treated PDMS, which has been treated with pluronic F-127 for 30 min to prevent particle adhesion. The number of particles in the sub-channels were counted and plotted as the particle output distribution. The mean of the distribution would correspond to the apparent particle size in the DLD device. The LOD of the vesicle was then determined from the apparent diameter difference with the uncoated beads.

Polymer vesicle preparation. Poly(butadiene-b-ethylene oxide) (PBd(1200)-PEO (600)) di-block co-polymer (P9089-BdEO, polymer source) was obtained to prepare vesicles, referred here as BD21, by film hydration method. Briefly, $5 \mathrm{mg}$ of polymer was dissolved in $200 \mu \mathrm{l}$ of chloroform, which was evaporated slowly by using stream of nitrogen in fume hood to make a thin film of polymer. To prepare dye labelled vesicles, Rhodamine B octadecyl ester perchlorate (RBOE, Sigma) dye was added in the polymer solution in chloroform before making the thin film. Polymer thin films (with and without RBOE) was vacuum dried for $4 \mathrm{~h}$. To this, 1 $\mathrm{mL}$ of $1 \times \mathrm{PBS}$ ( $\mathrm{pH} 7.2$ ) was added and stirred overnight on magnetic stirrers (IKA- 
Werke multi-position, RT 15 Power, Germany) at 400 r.p.m. to make vesicles that was downsized by extrusion (6 times through $0.45 \mu \mathrm{m}$ and 6 times through $0.22 \mu \mathrm{m}$ filter) and dialysed to remove the free RBOE. Both BD21 and BD21-RBOE vesicles were characterized for size and surface charge by ZetaSizer (Malvern Instrument, UK) and transmission electron microscopy (JEOL 2010F transmission electron microscope from Jeol Ltd, Tokyo, Japan). To confirm the incorporation of RBOE dye in vesicles, fluorescence intensity spectra was measured by fluorescence spectroscopy at excitation of $533 \mathrm{~nm}$.

Reconstitution of membrane protein in polymer vesicles. The vesicle was solubilized using $50 \mu \mathrm{L}$ of $10 \%$ Triton $\mathrm{x}-100$. To this vesicle-detergent-micelle suspension, Aqp1 membrane protein (ab114210, Abcam) was added in 1:1 weight ratio to vesicle and incubated for $1 \mathrm{~h}$ at $4{ }^{\circ} \mathrm{C}$. After this, $200 \mathrm{mg}$ of BioBeads SM-2 was added for detergent removal accompanied with incorporation of Aqp1 in polymer vesicles. The Aqp1 reconstituted vesicle was characterized for vesicle size and fluorescence intensity by DLS and microplate reader, respectively. Furthermore, confirmation for the presence, functionality, and quantity of Aqp1 in vesicle after reconstitution was done by immunoassay by attaching them on PS micro-beads, osmotic permeability assay, and BCA assay, respectively.

Polymer vesicles adsorption on beads. As prepared RBOE-BD21 vesicles were mixed with $1 \mu \mathrm{m}$-size PS beads and incubated at 1650 r.p.m. for $1 \mathrm{~h}$. After this, the beads were washed three times by centrifugation at 6000 r.p.m. for 5 mins. The vesicles attachment on to the beads was characterized by the fluorescence intensity measurement at $533 \mathrm{~nm}$ excitation by Infinite M200 PRO multimode microplate reader (Tecan) and bright-field and fluorescence microscopy imaging.

Antibody against Aqp1 conjugation on beads. Polyclonal rabbit anti-Aqp1 antibody against Aqp1 membrane protein (AQP001, Alomone lab) was diluted $20 \times$ and conjugated on $1 \mu \mathrm{m}$ PS-COOH beads surface via EDC/NHS coupling. Briefly, EDC/NHS was added to PS-COOH beads to activate the carboxyl groups and mixed under vortexing for $1 \mathrm{~h}$ at 1650 r.p.m., at $4{ }^{\circ} \mathrm{C}$. After activation, the beads were washed three times by centrifugation at 6000 r.p.m. for $5 \mathrm{~min}$. Before adding the antibody, the bead solution was subjected to probe sonication for 1 minute to ensure uniform dispersion of the beads. The antibody beads solution was incubated for $3 \mathrm{~h}$ at 1650 r.p.m. vortexing, at $4^{\circ} \mathrm{C}$. The conjugation of antibody to beads was confirmed by binding of mouse anti-rabbit antibody against rabbit antiAqp1 bound to Aqp1 protein.

Beads based detection of Aqp1 vesicles in suspension. Before adding the Aqp1vesicles for detection, antibody conjugated beads were incubated with blocker solution ( $1 \times$ PBS solution of $1 \%$ bovine serum albumin with $0.01 \%$ of pluronic), at 700 r.p.m. for $2 \mathrm{~h}$, room temperature to reduce the nonspecific binding. After blocking, antibody beads were washed thrice at 6000 r.p.m. for $5 \mathrm{~min}$ at $4{ }^{\circ} \mathrm{C}$ and mixed with vesicles with and without Aqp1 for incubation at 700 r.p.m. for $1 \mathrm{~h}$, room temperature. Next, the beads were washed thrice at 6000 r.p.m. for $5 \mathrm{~min}$ and mixed with primary antibody (mouse anti-Aqp1, Abcam ab117970, $20 \times$ dilution) at 700 r.p.m., 2 h, room temperature), washed thrice $\left(6000\right.$ r.p.m. for $5 \mathrm{~min}$ at $\left.4{ }^{\circ} \mathrm{C}\right)$ and mixed with secondary antibody (Alexa Fluor 647-conjugated goat anti-mouse IgG, Abcam ab150113, $20 \times$ dilution). Finally, the beads were washed thrice at 6000 r.p.m. for $5 \mathrm{~min}$ at $4{ }^{\circ} \mathrm{C}$ before characterization using bright-field and fluorescence microscopy imaging.

Beads-based detection of Aqp1 vesicles on DLD. The conjugated antibody is mixed with different concentration of vesicles with Aqp1 membrane protein and put in the sample inlet for separation with $0.1 \times \mathrm{PBS}$ as the buffer. The DLD device used was native PDMS device which has been treated with pluronic F-127 for 30 min to prevent particle adhesion. The number of particles in the sub-channels were counted and plotted as the particle output distribution. The mean of the distribution would correspond to the apparent particle size in the DLD device. The LOD of the vesicle is then determined from the apparent diameter difference with the uncoated beads.

Experimental setup. The fluid flow in the microfluidic device was driven by output fluid extraction using a Chemyx syringe pump and a Hamilton $100 \mu$ lglass syringe. The input sample and buffer reservoirs were exposed to atmospheric pressure. This method facilitates rapid washing and change of buffer solutions. The experiment was visualised using an upright microscope and the particle flows for input and output regions of the device were captured using high speed Phantom M310 camera. The frame rates used were 50fps for the detection zone at $\times 100$ magnification and $1000 \mathrm{fps}$ for the high-speed imaging of individual bead motion within the DLD pillars at $\times 600$ magnification. The number of particles flowing at different outlet sub-channels were counted and plotted as the particle output distribution for data analysis (Supplementary Note 3).

Particle trajectory modelling. The computational modelling was performed using COMSOL Multiphysics 5.0. The geometry of the simulation was set as the actual system 1 device with $6 \mu \mathrm{m}$ pillar, $4 \mu \mathrm{m}$ gap, and $0.75^{\circ}$ diameter with $250 \mu \mathrm{m} \mathrm{s}^{-1}$ velocity. The stokes flow module was used to get the velocity profile across the pillar and particle tracing of $1 \mu \mathrm{m}$ diameter at different position relative to the pillar, which mimic the position tracking from the experiment, was used to get the trace of the particle over time with the time-dependent study.

Data availability. The data that support the findings of this study are available from the corresponding author upon reasonable request.

Received: 22 August 2017 Accepted: 23 February 2018

Published online: 28 March 2018

\section{References}

1. Witwer, K. W. et al. Standardization of sample collection, isolation and analysis methods in extracellular vesicle research. J. Extracell. Vesicles 2, 20360 (2013).

2. Shen, J., Li, Y., Gu, H., Xia, F. \& Zuo, X. Recent development of sandwich assay based on the nanobiotechnologies for proteins, nucleic acids, small molecules, and ions. Chem. Rev. 114, 7631-7677 (2014).

3. Kosaka, P. M. et al. Detection of cancer biomarkers in serum using a hybrid mechanical and optoplasmonic nanosensor. Nat. Nanotechnol. 9, 1047-1053 (2014)

4. Cheng, Z. et al. Simultaneous detection of dual prostate specific antigens using surface-enhanced Raman scattering-based immunoassay for accurate diagnosis of prostate cancer. ACS Nano 11, 4926-4933 (2017).

5. Yang, L., Li, P., Liu, H., Tang, X. \& Liu, J. A dynamic surface enhanced Raman spectroscopy method for ultra-sensitive detection: from the wet state to the dry state. Chem. Soc. Rev. 44, 2837-2848 (2015).

6. Krishnan, S., Mani, V., Wasalathanthri, D., Kumar, C. V. \& Rusling, J. F. Attomolar detection of a cancer biomarker protein in serum by surface plasmon resonance using superparamagnetic particle labels. Angew. Chem. Int. Ed. Engl. 50, 1175-1178 (2011).

7. Im, H. et al. Label-free detection and molecular profiling of exosomes with a nano-plasmonic sensor. Nat. Biotechnol. 32, 490-495 (2014).

8. Gaster, R. S. et al. Matrix-insensitive protein assays push the limits of biosensors in medicine. Nat. Med. 15, 1327-1332 (2009).

9. Fu, Y. et al. Highly sensitive detection of protein biomarkers with organic electrochemical transistors. Adv. Mater. 29, 1703787 (2017).

10. Deng, X. et al. A highly sensitive immunosorbent assay based on biotinylated graphene oxide and the quartz crystal microbalance. ACS Appl. Mater. Interfaces 8, 1893-1902 (2016).

11. Yang, S., Dai, X., Stogin, B. B. \& Wong, T.-S. Ultrasensitive surface-enhanced Raman scattering detection in common fluids. Proc. Natl Acad. Sci. 113, 268-273 (2016).

12. McGrath, J., Jimenez, M. \& Bridle, H. Deterministic lateral displacement for particle separation: a review. Lab. Chip. 14, 4139-4158 (2014).

13. Huang, L. R., Cox, E. C., Austin, R. H. \& Sturm, J. C. Continuous particle separation through deterministic lateral displacement. Science 304, 987-990 (2004).

14. Nagrath, $\mathrm{S}$. et al. Isolation of rare circulating tumour cells in cancer patients by microchip technology. Nature 450, 1235-1239 (2007).

15. Salafi, T., Zeming, K. K. \& Zhang, Y. Advancements in microfluidics for nanoparticle separation. Lab. Chip. 17, 11-33 (2017).

16. Davis, J. A. et al. Deterministic hydrodynamics: taking blood apart. Proc. Natl Acad. Sci. USA 103, 14779-14784 (2006).

17. Kim, S.-C. et al. Broken flow symmetry explains the dynamics of small particles in deterministic lateral displacement arrays. Proc. Natl Acad. Sci. 114, E5034-E5041 (2017).

18. Wunsch, B. H. et al. Nanoscale lateral displacement arrays for the separation of exosomes and colloids down to $20 \mathrm{~nm}$. Nat. Nanotechnol. 11, 936-940 (2016).

19. Beech, J. P. et al. Separation of pathogenic bacteria by chain length. Anal. Chim. Acta 1000, 223-231 (2017).

20. Henry, E. et al. Sorting cells by their dynamical properties. Sci. Rep. 6, 34375 (2016).

21. Zeming, K. K., Thakor, N. V., Zhang, Y. \& Chen, C.-H. Real-time modulated nanoparticle separation with an ultra-large dynamic range. Lab. Chip. 16, 75-85 (2016)

22. Donaldson, S. H. Jr et al. Asymmetric electrostatic and hydrophobic-hydrophilic interaction forces between mica surfaces and silicone polymer thin films. ACS Nano 7, 10094-10104 (2013).

23. Xu, L.-C. \& Logan, B. E. Interaction forces between colloids and proteincoated surfaces measured using an atomic force microscope. Environ. Sci. Technol. 39, 3592-3600 (2005). 
24. Beattie, J. K. The intrinsic charge on hydrophobic microfluidic substrates. Lab. Chip. 6, 1409-1411 (2006)

25. Barisik, M., Atalay, S., Beskok, A. \& Qian, S. Size dependent surface charge properties of silica nanoparticles. J. Phys. Chem. C. 118, 1836-1842 (2014).

26. Kosmulski, M. Positive electrokinetic charge of silica in the presence of chlorides. J. Colloid Interface Sci. 208, 543-545 (1998).

27. Atalay, S., Barisik, M., Beskok, A. \& Qian, S. Surface charge of a nanoparticle interacting with a flat substrate. J. Phys. Chem. C. 118, 10927-10935 (2014).

28. Piliarik, M. \& Sandoghdar, V. Direct optical sensing of single unlabeled small proteins and super-resolution microscopy of their binding sites. Nat. Commun. 5, 4495 (2014).

29. Barbosa, L. R. et al. The importance of protein-protein interactions on the pHinduced conformational changes of bovine serum albumin: a small-angle Xray scattering study. Biophys. J. 98, 147-157 (2010).

30. Yu, H., Qiu, X., Nunes, S. P. \& Peinemann, K.-V. Biomimetic block copolymer particles with gated nanopores and ultrahigh protein sorption capacity. Nat. Commun. 5, 4110 (2014).

31. Arlett, J. L., Myers, E. B. \& Roukes, M. L. Comparative advantages of mechanical biosensors. Nat. Nanotechnol. 6, 203 (2011).

32. $\mathrm{Wu}, \mathrm{B}$. et al. Detection of C-reactive protein using nanoparticle-enhanced surface plasmon resonance using an aptamer-antibody sandwich assay. Chem. Commun. 52, 3568-3571 (2016).

33. Tkach, M. \& Théry, C. Communication by extracellular vesicles: where we are and where we need to go. Cell 164, 1226-1232 (2016).

34. Sung, B. H., Ketova, T., Hoshino, D., Zijlstra, A. \& Weaver, A. M. Directional cell movement through tissues is controlled by exosome secretion. Nat. Commun. 6, 7164 (2015)

35. Hoshino, D. et al. Exosome secretion is enhanced by invadopodia and drives invasive behavior. Cell Rep. 5, 1159-1168 (2013).

36. Wiley, R. D. \& Gummuluru, S. Immature dendritic cell-derived exosomes can mediate HIV-1 trans infection. Proc. Natl Acad. Sci. USA 103, 738-743 (2006).

37. Li, J. et al. Exosomes mediate the cell-to-cell transmission of IFN-[alpha]induced antiviral activity. Nat. Immunol. 14, 793-803 (2013).

38. Almén, M. S., Nordström, K. J., Fredriksson, R. \& Schiöth, H. B. Mapping the human membrane proteome: a majority of the human membrane proteins can be classified according to function and evolutionary origin. BMC Biol. 7, 50 (2009).

39. Sandfeld-Paulsen, B. et al. Exosomal proteins as prognostic biomarkers in non-small cell lung cancer. Mol. Oncol. 10, 1595-1602 (2016).

40. Kowal, J. et al. Proteomic comparison defines novel markers to characterize heterogeneous populations of extracellular vesicle subtypes. Proc. Natl Acad. Sci. USA 113, E968-E977 (2016).

41. Van Der Vlist, E. J., Nolte, E. N., Stoorvogel, W., Arkesteijn, G. J. \& Wauben, M. H. Fluorescent labeling of nano-sized vesicles released by cells and subsequent quantitative and qualitative analysis by high-resolution flow cytometry. Nat. Protoc. 7, 1311-1326 (2012).

42. Jeong, S. et al. Integrated magneto-electrochemical sensor for exosome analysis. ACS Nano 10, 1802-1809 (2016).

43. Shao, H. et al. Protein typing of circulating microvesicles allows real-time monitoring of glioblastoma therapy. Nat. Med. 18, 1835-1840 (2012).

44. Discher, B. M. et al. Polymersomes: tough vesicles made from diblock copolymers. Science 284, 1143-1146 (1999).

45. Christian, D. A. et al. Spotted vesicles, striped micelles and Janus assemblies induced by ligand binding. Nat. Mater. 8, 843-849 (2009).

46. Tanner, P. et al. Polymeric vesicles: from drug carriers to nanoreactors and artificial organelles. Acc. Chem. Res. 44, 1039-1049 (2011).

47. Blanc, L. et al. The water channel aquaporin-1 partitions into exosomes during reticulocyte maturation: implication for the regulation of cell volume. Blood 114, 3928-3934 (2009).

48. Papadopoulos, M. C. \& Verkman, A. S. Aquaporin water channels in the nervous system. Nat. Rev. Neurosci. 14, 265-277 (2013).

49. Ollivon, M., Lesieur, S., Grabielle-Madelmont, C. \& Mt, Paternostre Vesicle reconstitution from lipid-detergent mixed micelles. Biochim. Et. Biophys. Acta (BBA) Biomembr. 1508, 34-50 (2000).
50. Zech, D., Rana, S., Büchler, M. W. \& Zöller, M. Tumor-exosomes and leukocyte activation: an ambivalent crosstalk. Cell Commun. Signal. 10, 37 (2012).

51. Beltrami, C. et al. Human pericardial fluid contains exosomes enriched with cardiovascular-expressed microRNAs and promotes therapeutic angiogenesis. Mol. Ther. 25, 679-693 (2017).

52. Song, X. et al. Cancer cell-derived exosomes induce mitogen-activated protein kinase-dependent monocyte survival by transport of functional receptor tyrosine kinases. J. Biol. Chem. 291, 8453-8464 (2016).

53. Inglis, D. W., Davis, J. A., Austin, R. H. \& Sturm, J. C. Critical particle size for fractionation by deterministic lateral displacement. Lab. Chip. 6, 655-658 (2006).

54. Zeming, K. K., Salafi, T., Chen, C.-H. \& Zhang, Y. Asymmetrical deterministic lateral displacement gaps for dual functions of enhanced separation and throughput of red blood cells. Sci. Rep. 6, 22934 (2016).

55. Butt, H.-J., Cappella, B. \& Kappl, M. Force measurements with the atomic force microscope: technique, interpretation and applications. Surf. Sci. Rep. 59, $1-152(2005)$

\section{Acknowledgements}

We acknowledge the funding support from Singapore Ministry of Education AcRF Tier 1 and Tier 3 funding (R397-000-270-114, MOE2016-T3-1-004). We also acknowledge Scholarship from NUS Graduate school for integrative science and engineering and infrastructural support from the National University of Singapore.

\section{Author contributions}

K.K.Z. and T.S. contributed equally to the work. K.K.Z. contributed to the conception, device design, fabrication, and protein detection experiments. T.S. contributed to the Comsol simulations, antibody-based protein detection, vesicle detection, and post-review experiments. S.S. contributed to the vesicle fabrication, characterization, and detection. Y.Z. contributed to the overall planning, project conception, data analysis, and writing of the manuscript.

\section{Additional information}

Supplementary Information accompanies this paper at https://doi.org/10.1038/s41467018-03596-z.

Competing interests: The authors declare no competing interests.

Reprints and permission information is available online at http://npg.nature.com/ reprintsandpermissions/

Publisher's note: Springer Nature remains neutral with regard to jurisdictional claims in published maps and institutional affiliations.

cc) (i) Open Access This article is licensed under a Creative Commons BY Attribution 4.0 International License, which permits use, sharing, adaptation, distribution and reproduction in any medium or format, as long as you give appropriate credit to the original author(s) and the source, provide a link to the Creative Commons license, and indicate if changes were made. The images or other third party material in this article are included in the article's Creative Commons license, unless indicated otherwise in a credit line to the material. If material is not included in the article's Creative Commons license and your intended use is not permitted by statutory regulation or exceeds the permitted use, you will need to obtain permission directly from the copyright holder. To view a copy of this license, visit http://creativecommons.org/ licenses/by/4.0/.

(C) The Author(s) 2018 